\title{
Evaluación de Competencias a través de una Experiencia de flipped classrom en Programación en la Universidad Nacional de La Matanza
}

\author{
Sergio Daniel Conde \\ Universidad Nacional de La Matanza, Argentina \\ sergiodanielconde@fibertel.com.ar

\section{Santiago Igarza} \\ Universidad Nacional de La Matanza, Argentina \\ asigarza@unlam.edu.ar
}

Presentación 18/11/2016

Aprobación 20/07/2017

\section{Resumen}

El objetivo general de la investigación ha sido la utilización de diferentes herramientas de lenguajes de programación con la utilización de Flpped Classroom en la Universidad Nacional de la Matanza en Asignatura de Programación favoreciendo la aplicación y evaluación de competencias.

A partir de esa finalidad se ha propuesto crear los recursos y materiales necesarios para poder desarrollar una experiencia de "Flipped Classroom" para los cursos durante el año 2013-2016 y promover el uso de FlippedClasroom que es una metodología educativa que implica "dar la vuelta a la clase".

Se parte de la Hipótesis: La aplicación de Flipped Classroom en estudiantes de la carrera de Ingeniería en Informática de la Universidad Nacional de la Matanza favorece la aplicación y evaluación de competencias del alumno en la Asignatura Programación. El tipo de diseño es cuantitativo / cualitativo. Por último se procede a validar la muestra con los resultados obtenidos.

Palabras clave: Aprendizaje, Clase Invertida, Educación Universitaria, Programación

\begin{abstract}
The general objective of the research has been the use of different programming language tools with the use of Flipped Classroom in the National University
\end{abstract}


of La Matanza in Programming Subject favoring the application and evaluation of competences.

From that end, it has been proposed to create the necessary resources and materials to develop a Flipped Classroom experience for the courses during 2013-2016 and to promote the use of Flipped Clasroom which is an educational methodology that implies "giving the Back to class ".

It is part of the Hypothesis: The application of Flipped Classroom in students of the degree in Computer Engineering at the Universidad Nacional de la Matanza favors the application and evaluation of the student's competences in the Programming Subject. The type of design is quantitative / qualitative Finally, the sample is validated with the results obtained.

Keywords: Learning, Inverted Class, University Education, Programming

\section{Introducción}

El objetivo de la investigación es demostrar la evaluación de competencias por intermedio de Flipped Classroom en estudiantes de la carrera de Ingeniería en Informática de la Universidad Nacional de la Matanza favoreciendo la aplicación de competencias.

Se parte de la Hipótesis: La aplicación o Flipped Classroom en estudiantes de la carrera de Ingeniería en Informática de la Universidad Nacional de la Matanza favorece la aplicación y evaluación de competencias del alumno en la Asignatura Programación.

Se aplica una metodología detallada donde se integran diferentes elementos que permiten identificar el análisis cualitativo y cuantitativo comparando diferentes variables que se encuentran presentes en las competencias a evaluar por intermedio de Flipped Classroom en estudiantes de la carrera de Ingeniería en Informática de la Universidad Nacional de la Matanza

Por último para terminar se procede a validar la muestra con los resultados obtenidos.

El tipo de diseño es cuantitativo / cualitativo

\section{Marco Teórico}

\section{Las Redes Sociales}

Las redes sociales se convirtieron en los últimos años en una revolución dinámica por su frecuente y continua expansión donde se generan numerosas fuentes de iteración de numerosos grupos sociales que comparten intereses comunes y especializados.

La aparición de la web 2.0 en educación tuvo un impacto positivo porque permite crear diferentes comunidades virtuales de aprendizaje y de una multitud de redes de colaboración entre iguales [1].

Se puede definir a las redes sociales como un conjunto de asociaciones de personas 
unidas por motivos heterogéneos que conforman una estructura compuesta por numerosos nodos unidos sinérgicamente entre ellos por diversos tipos de relación. [2].

Las redes sociales se relacionan mucho con el aprendizaje colaborativo que resulta como instrumento de aplicación una herramienta muy útil donde se encuentran las siguientes ventajas:

- El trabajo colaborativo incrementa la motivación.

- Favorece la obtención de mayores niveles de rendimiento académico complementando la retroalimentación positiva del aprendizaje individual y el aprendizaje grupal.

- Favorece la incorporación del pensamiento crítico.

- Favorece la diversidad de los conocimientos y las experiencias que se adquieren.[3].

\section{Aprendizaje Invertido}

Según Bergmann, Sams (2012) y Lemmer (2013), la clase invertida es un modelo pedagógico apoyado en las teorías del aprendizaje activo y responde a las necesidades de modernizar el aprendizaje mediante una metodología efectiva que reemplace la clase tradicional y donde se faciliten materiales instructivos pre-elaborados para que el estudiante estudie y asimile el contenido a su ritmo.[4].

Desde una perspectiva práctica Flipped-Classroom se ha definido como un modelo de enseñanza en donde la presentación de los contenidos de una disciplina se realiza a través de videos grabados por el profesor y que este deja disponibles a sus estudiantes utilizando, para su almacenamiento, herramientas de Internet[5].

\section{Perspectivas del Aprendizaje}

En el aprendizaje las personas no entienden, ni utilizan de manera inmediata la información que se les proporciona. En cambio el individuo siente la necesidad de construir su propio el conocimiento, generando el mismo por intermedio de la experiencia. La experiencia es el instrumento que conduce a la creación de esquemas que son modelos mentales que se almacenan en las mentes.

Los esquemas mentales almacenados en la mente van cambiando, agregando información y se van convirtiendo cada vez más sofisticados por intermedio de dos factores elementales: la asimilación y el alojamiento. [6].

El constructivismo social tiene como eje central que cada función en el desarrollo cultural de las personas aparece a nivel social y luego a nivel individual.

En un primer momento entre un grupo de personas interpsicológico y luego dentro de si mismo o intrapsicológico.

Estos elementos se aplican tanto en la atención voluntaria, como en la memoria lógica y en la formación de los conceptos.[7].

El profesor en la web en lugar de aportar conocimientos, tiene el rol de participar en la generación del conocimiento junto al estudiante de forma construida y compartida. El estudiante asume un rol donde entiende a la perfección que los procesos 
centrales del aprendizaje son los procesos de organización y la comprensión fundamental del material didáctico compartido debido a que el aprendizaje es el resultado de la interpretación y transformación de los materiales didácticos recibidos.

En este proceso de aprendizaje el estudiante es el actor fundamental como protagonista del aprendizaje [8].

Los estudiantes que se encuentran comprometidos en el proceso de aprendizaje en la web se pueden resaltar las siguientes características:

- Responsables del Aprendizaje

- Motivados por el Aprendizaje

- Colaborativos

- Estratégicos

Estas características junto con el nuevo rol del profesor son los elementos que contribuyen que la educación sea para toda la vida, convirtiéndose en un elemento esencial la relación sinérgica entre alumno - profesor [9].

Spencer y Spencer (1999): entienden la competencia como una "característica subyacente en el individuo que está causalmente relacionada con un estándar de efectividad y/o una performance superior en un trabajo o situación. En la definición de Spencer y Spencer puede distinguirse tres elementos importantes:

En primer lugar la idea de característica subyacente resaltando que en parte competencia supone una parte profunda de la personalidad y predice comportamiento en una amplia variedad de situaciones y desafíos laborales.

En segundo lugar, se afirma que está causalmente relacionada, lo que quiere expresar que la competencia origina o anticipa el comportamiento y el desempeño. Finalmente se usa el término de estándar de efectividad, que significa que puede determinarse si alguien desempeña la competencia bien o mal al referenciarlo con un criterio estándar.[10].

Según la OIT en el año 2000 define a la competencia como la capacidad efectiva para llevar a cabo exitosamente una actividad laboral plenamente identificada. Las competencias son el conjunto de conocimientos, procedimientos y actitudes combinados, coordinados e integrados en la acción adquiridos a través de la experiencia formativa y no formativa que permite al individuo resolver problemas específicos de forma autónoma y flexible en contextos singulares.

\section{Elementos del Trabajo y Metodología}

\section{Organización:}

Se organizó a los alumnos en equipos de dos integrantes con una computadora a disposición en la Asignatura Programación en la modalidad de Taller.

La aplicación se realiza con un promedio de 26 alumnos por cada curso que cursaron la Asignatura Programación durante el período 2013 hasta el primer cuatrimestre del año 2016 abarcando siete cuatrimestres para dieciséis cursos en un total de 576 alumnos. 
Se deja en claro que la evaluación de competencias se puede realizar porque se desarrollan páginas reales que se suben el un hosting gratis o un hosting pago para diferentes clientes que necesitan el diseño de una página web.

Para detectar las competencias a evaluar se tomaron estándares que contiene la página: http://www.w3c.es/

Se tienen en cuenta las siguientes competencias:

Conocer el potencial y limitaciones de cada herramienta utilizada.

Conocer la aplicación de Html, Css, y Java Script.

Organizar y presentar el diseño web en forma legible y adecuada.

A nivel Identificación del sitio web:

¿Es claro el nombre del sitio web?

¿El autor está claramente identificado?

Contenidos del sitio web:

El sitio web tiene: ¿títulos y encabezamientos adecuados claros y descriptivos?

¿Contiene textos, imágenes, sonidos y multimedios?

¿Tiene mapas adecuados?

Estructura y Diseño del sitio web:

¿Es rápido el acceso al sitio web?

¿Las pantallas tienen un diseño general claro y atractivo?

¿Los iconos representan en forma clara su función?

\section{Primera Etapa:}

El alumno en el aula virtual tiene a disposición diferentes videos explicativos donde se ve la aplicación detallada de HTML.

Se utiliza la clase presencial para dar apoyo a conceptos básicos de diseño web comenzando con HTML que se vieron en el video.

\section{Segunda Etapa:}

El alumno en el aula virtual tiene a disposición diferentes videos explicativos donde se ve la aplicación detallada de CSS con acceso a diferentes links para verificar el adecuado diseño de una página web.

A partir de la incorporación de diseño se utilizan las clases presenciales para consultar dudas y desarrollar la construcción de un sitio web aplicando los conceptos aprendidos en el video y los links de consultas integrando HTML y CSS.

\section{Tercera Etapa:}

El alumno en el aula virtual tiene a disposición diferentes videos explicativos donde se ve la aplicación detallada de Java Script con acceso a diferentes links para verificar el adecuado diseño dinámico y la incorporación de mapas y formularios de una página web.

A partir de la incorporación de diseño dinámico con Java Script.

Se utilizan las clases presenciales para consultar dudas y desarrollar la construcción de un sitio web aplicando los conceptos aprendidos en el video y los links de consultas integrando HTML, CSSy Java Script.

\section{Cuarta Etapa:}

Se utiliza la clase presencial como soporte donde el alumno desarrolla el sitio web aplicando la integración de todos los elementos aprendidos en el desarrollo de la Asignatura. 
En cada etapa existen videos explicativos que se encuentran subidos en dropbox si el alumno tiene inconvenientes en acceder al aula virtual.

Se evalúan las competencias establecidas.

1)Diseño web adecuado.

2)Nombre del Sitio web. Autor Identificado.

3)¿Títulos y encabezamientos adecuados claros y descriptivos?

4)¿Contiene textos, imágenes, sonidos y multimedios?

5)¿Tiene mapas adecuados?

6)¿Es rápido el acceso al sitio web?

7)¿Las pantallas tienen un diseño general claro y atractivo?

8)¿Los iconos representan en forma clara su función?

\section{Resultados}

A continuación se muestran los gráficos de resultados logrados:

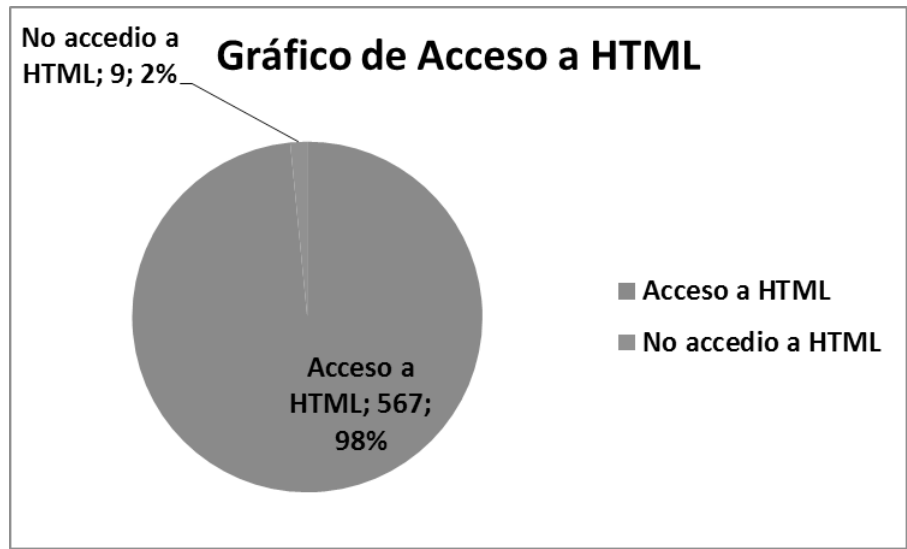

Gráfico 1: Acceso a HTML

Se observa que de 576 (quinientos sesenta y seis), 567 alumnos accedieron a HTML con un porcentaje del $98 \%$. Se observa que 9 (nueve) alumnos no accedieron a HTML con un porcentaje del $2 \%$.

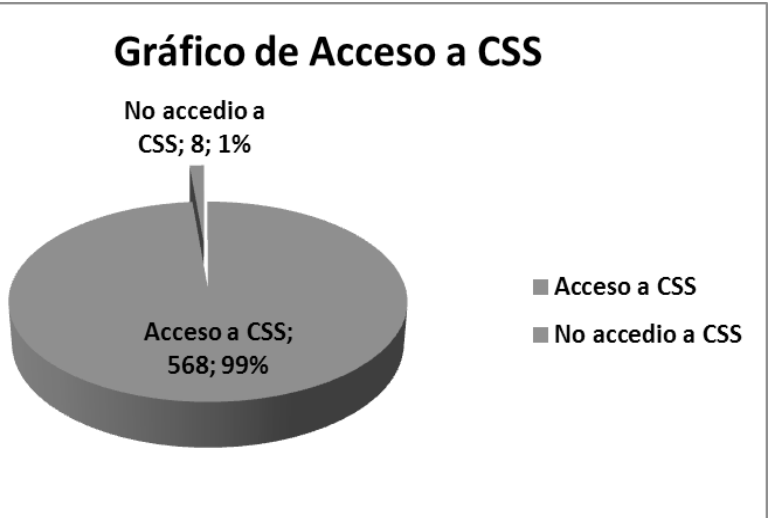

Gráfico 2: Acceso a CSS. 
Se observa que de 576 (quinientos sesenta y seis), 568 alumnos accedieron a CSS con un porcentaje del $99 \%$. Se observa que 8 (ocho) alumnos no accedieron a CSS con un porcentaje del $1 \%$.

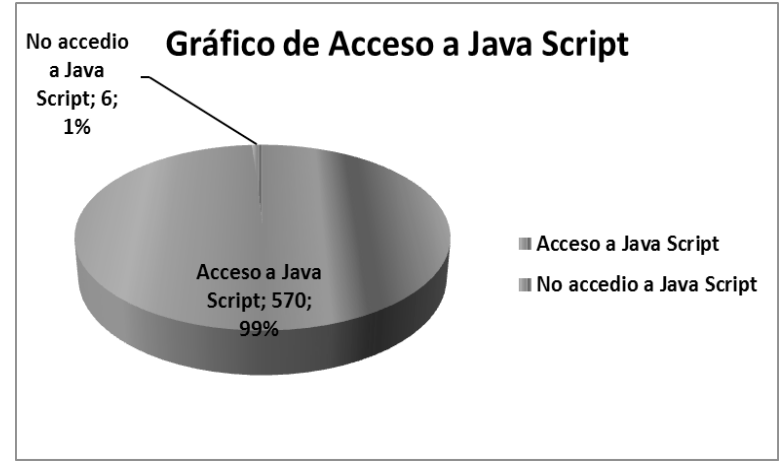

Gráfico 3: Acceso a Java Script.

Se observa que de 576 (quinientos sesenta y seis), 570 alumnos accedieron a JAVA SCRIPT con un porcentaje del 99\%. Se observa que 6(seis) alumnos no accedieron a JAVA SCRIPT con un porcentaje del $1 \%$.

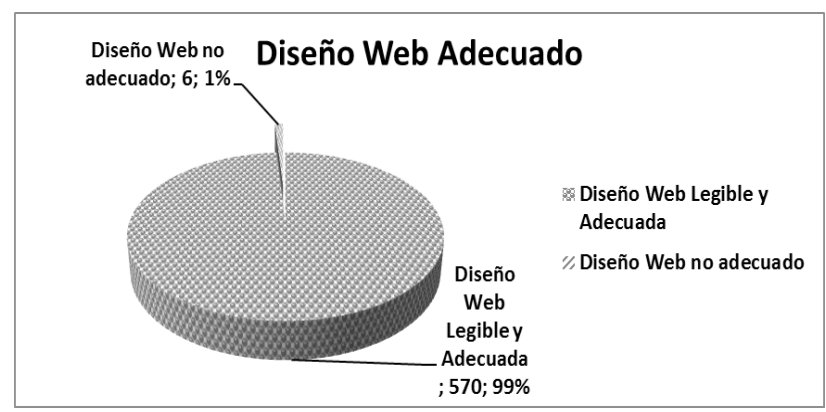

Gráfico 4: Diseño Web Adecuado.

Se observa que de 576 (quinientos sesenta y seis), 570 alumnos realizaron un diseño web adecuado con un porcentaje del $99 \%$. Se observa que 6(seis) alumnos no realizaron un diseño web adecuado con un porcentaje del $1 \%$.

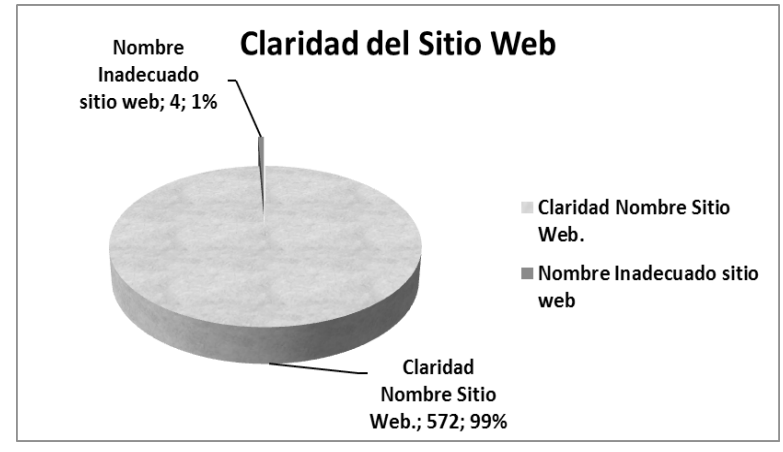

Gráfico 5: Claridad del sitio Web. 
Se observa que de 576 (quinientos sesenta y seis), 572 alumnos realizaron una claridad en el nombre del sitio web adecuado con un porcentaje del $99 \%$. Se observa que 4(cuatro) alumnos no realizaron un nombre adecuado del sitio web con un porcentaje del $1 \%$.

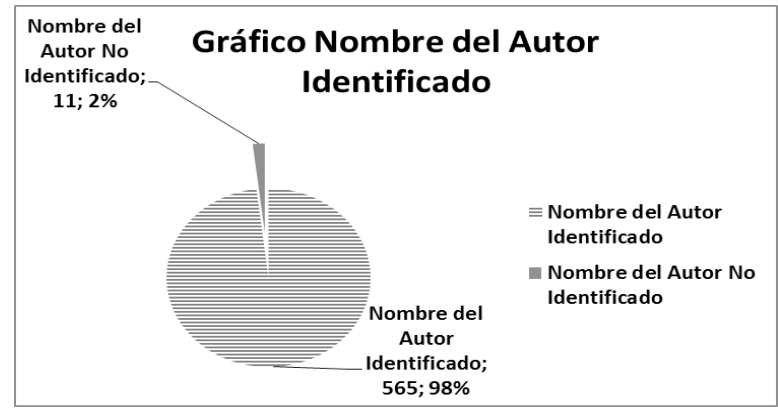

Gráfico 6: Nombre del Autor Identificado.

Se observa que de 576 (quinientos sesenta y seis), 565 alumnos colocaron el nombre del autor con un porcentaje del $98 \%$. Se observa que 11(once) alumnos no colocaron el nombre del autor con un porcentaje del $2 \%$.

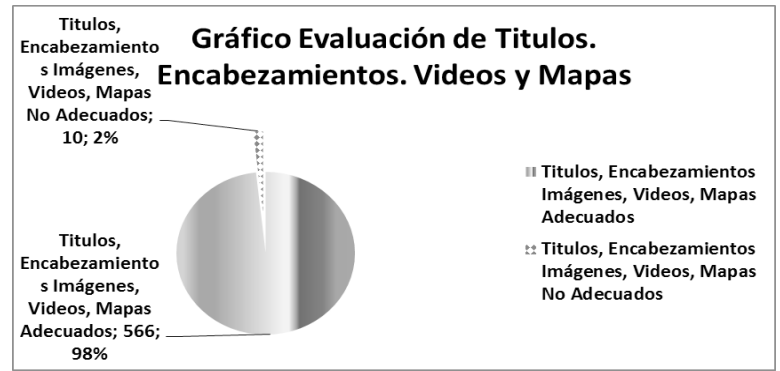

Gráfico 7: Evaluación de Títulos, encabezamientos, videos y mapas.

Se observa que de 576 (quinientos sesenta y seis), 566 alumnos colocaron títulos, encabezamientos, videos y mapas con un porcentaje del $99 \%$. Se observa que 10(diez) alumnos no colocaron títulos, encabezamientos, videos y mapas con un porcentaje del $2 \%$.

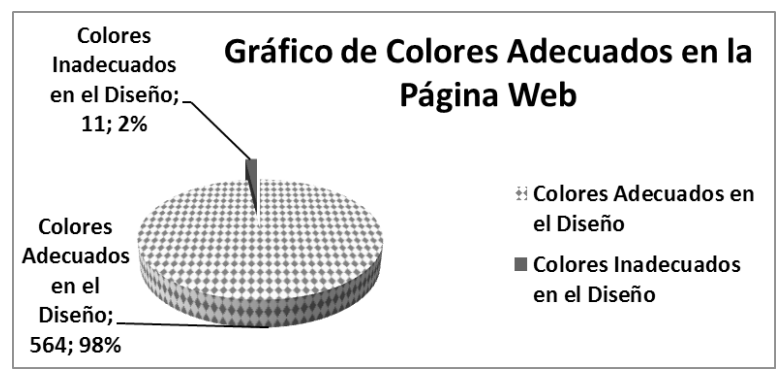

Gráfico 8: Colores Adecuados en la Página Web. 
Se observa que de 576 (quinientos sesenta y seis), 564 alumnos colocaron colores adecuados en el diseño con un porcentaje del $98 \%$.

Se observa que 11(once) alumnos no colocaron colores adecuados en el diseño con un porcentaje del $2 \%$.

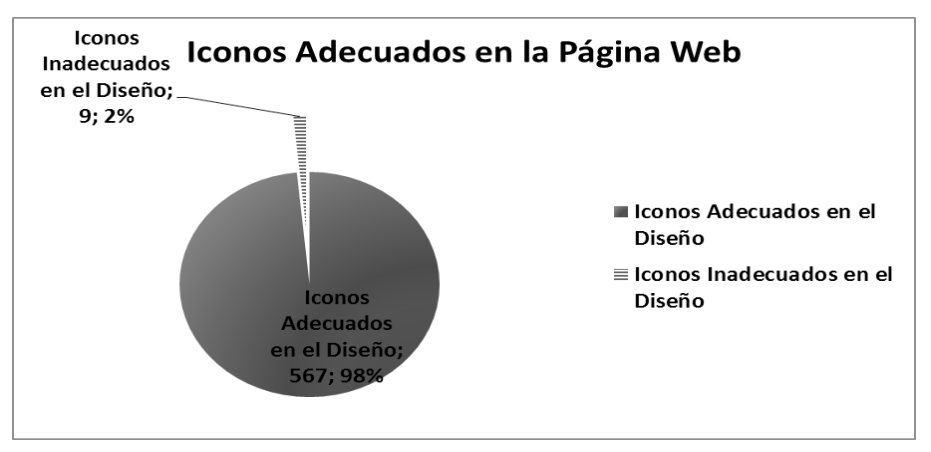

Gráfico 9: Iconos Adecuados en la Página Web.

Se observa que de 576 (quinientos sesenta y seis), 567 alumnos colocaron iconos adecuados con un porcentaje del $98 \%$.

Se observa que 9(nueve) alumnos no colocaron iconos adecuados con un porcentaje del $2 \%$.

\section{Validando Muestra:}

Para validar la muestra se tiene en cuenta la siguiente tabla:

\begin{tabular}{|l|c|c|}
\hline & $\begin{array}{c}\text { Competencias } \\
\text { Aplicadas }\end{array}$ & $\begin{array}{c}\text { Competencias No } \\
\text { Aplicadas }\end{array}$ \\
\hline Diseño Web Legible y Adecuada & 570 & 6 \\
\hline Claridad Nombre Sitio Web. & 572 & 4 \\
\hline Nombre del Autor Identificado & 565 & 11 \\
\hline Titulos, Encabezamientos Imágenes, Videos, Mapas Adecuados & 566 & 10 \\
\hline Colores Adecuados en el Diseño & 564 & 12 \\
\hline conos Adecuados en el Diseño & 567 & 9 \\
\hline Apliación de HTML & 567 & 9 \\
\hline Aplicación de CSS & 568 & 8 \\
\hline Aplicación de JAVA SCRIPT & 570 & 6 \\
\hline Media & 567,67 & 8,33 \\
\hline Desviación Estándar & 2,60 & 2,60 \\
\hline Desviación Estándar/Media & 0,005 & 0,312 \\
\hline & Muestra & \\
\hline & Validada & \\
\hline
\end{tabular}

Tabla 1: Competencias Aplicadas y Competencias No Aplicadas.

La muestra queda validada al observar que el resultado de la división entre la desviación Estandar y la media es menor a los contenidos evaluados $(0,005$ es menor a 0,312$)$.

Por lo tanto queda validada la muestra. 


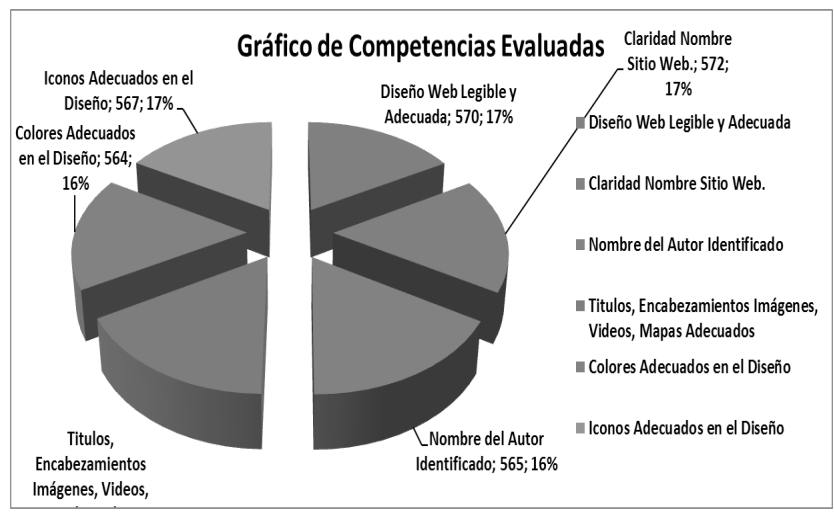

Gráfico 10: Competencias Aplicadas

Analizando el Gráfico anterior de Competencias Aplicadas ordenados de mayor a menor se obtiene:

\begin{tabular}{|l|c|c|}
\hline & $\begin{array}{c}\text { Competencias } \\
\text { Aplicadas }\end{array}$ & Porcentaje \\
\hline Diseño Web Legible y Adecuada & 570 & $17 \%$ \\
\hline Claridad Nombre Sitio Web. & 572 & $17 \%$ \\
\hline Titulos, Encaberamientos Imágenes, Videos, Mapas Adecuados & 566 & $17 \%$ \\
\hline Iconos Adecuados en el Diseño & 567 & $17 \%$ \\
\hline Nombre del Autor Identificado & 565 & $16 \%$ \\
\hline Colores Adecuados en el Diseño & 564 & $16 \%$ \\
\hline
\end{tabular}

Tabla 2: Competencias Aplicadas ordenadas de mayor a menor.

Analizando la tabla se observa que los siguientes ítems son los que menos se aplicaron: Nombre del autor y Colores Adecuados en el Diseño con un $16 \%$.

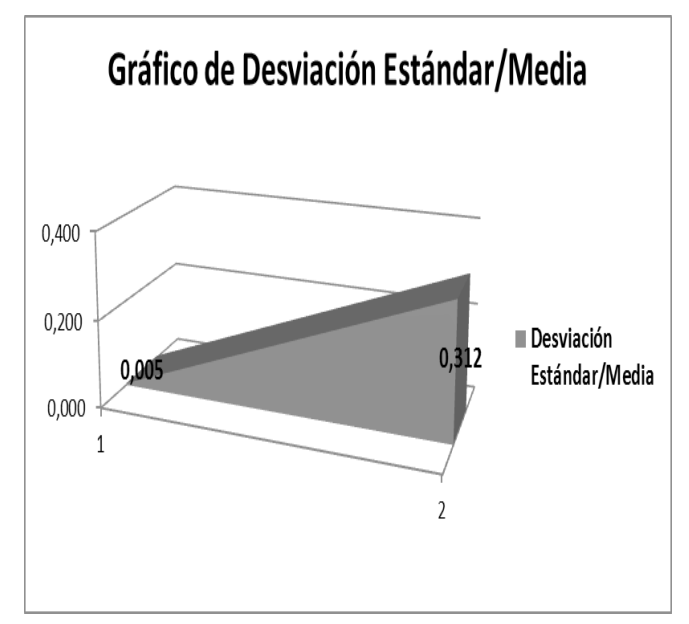

Gráfico 11: Desviación Estandar de Competencias No Aplicadas y Competencias Aplicadas. 
El gráfico 11 identifica que se obtiene una Desviación Estándar de 0,005 en Competencias Aplicadas y una Desviación Estándar de 0,312 en Competencias no aplicadas.

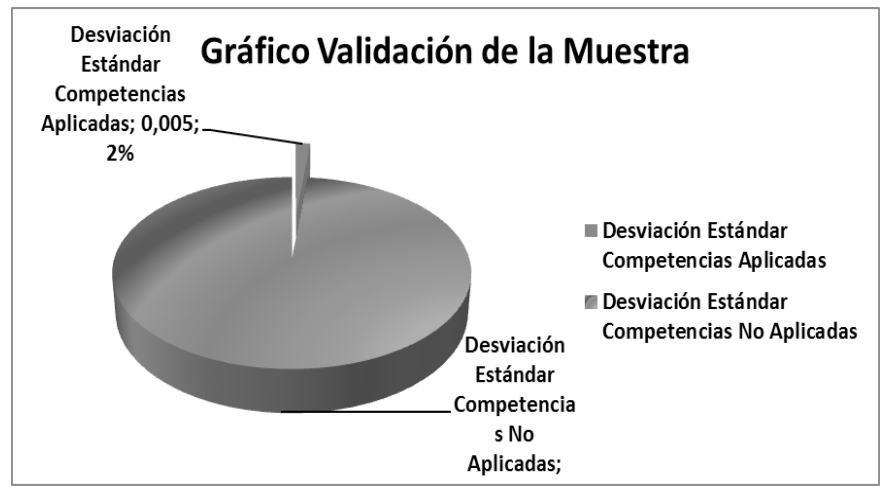

Gráfico 12: Validación de Muestra.

Realizando la división entre Desviación Estándar y la Media se obtiene 0,005 en Competencias Aplicadas y 0,031 en Competencias No Aplicadas según lo observado en la Tabla 1 y en el Gráfico 12

Analizando el contenido de la tabla 1 y teniendo en cuenta diferentes parámetros de contenidos se obtiene una media en Competencias Aplicadas de 567,67 y Competencias No Aplicadas de 8,33.

La desviación estándar obtenida en Competencias Aplicadas y No Aplicadas es de 2,60 .

El promedio entre desviación estándar y la media en Competencias Aplicadas es de 0,005 y de 0,031 en Competencias No Aplicadas.

Por lo tanto queda verificado que al ser menor las Competencias Aplicadas que las Competencias No Aplicadas queda validada la muestra.

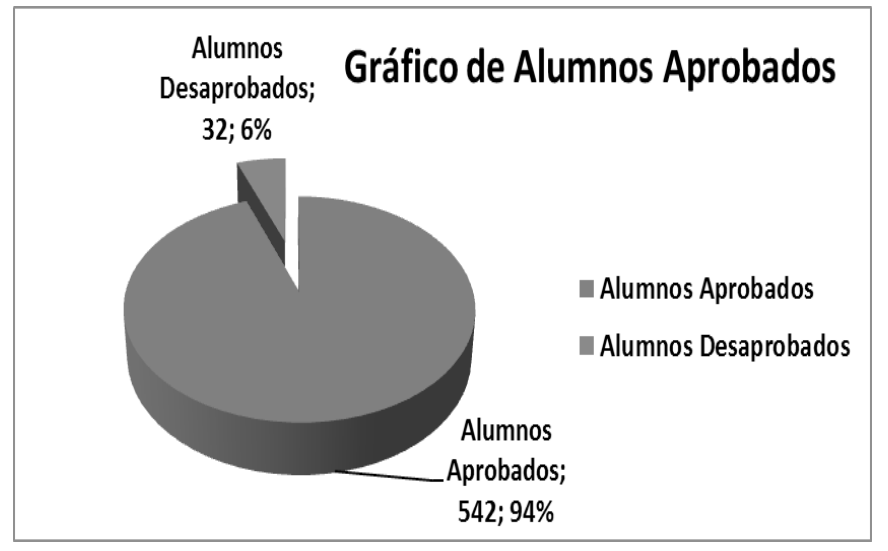

Gráfico 13: Alumnos Aprobados.

El gráfico 13(trece) identifica que aprobaron la asignatura 542 alumnos con un porcentaje del $94 \%$ y desaprobaron 32 (treinta y dos) con un porcentaje del $6 \%$. 


\section{Conclusión}

Partiendo de la Hipótesis: La evaluación de competencias a través de Flipped Classroom en estudiantes de la carrera de Ingeniería en Informática de la Universidad Nacional de la Matanza favorece la aplicación de competencias del alumno en la Asignatura Programación que el trabajo realizado por intermedio de videos y diferentes links en cada uno de los temas desarrollados se observa lo siguiente:

- Detectar la cantidad de alumnos que ingresan a consultar la bibliografía de la Asignatura por intermedio de videos como un instrumento de conexión con el aprendizaje a desarrollar.

- Detectar la cantidad de alumnos que no ingresan a consultar la bibliografía de la Asignatura.

- Realizar el seguimiento en las clases de aula de la aplicación de cada uno de los temas elaborados en el aula virtual.

- Realizar el seguimiento del desarrollo del sitio web aplicando cada uno de los contenidos elaborados en los videos.

- Realizar el seguimiento de las competencias aplicadas en el diseño del sitio web aplicando cada uno de los contenidos elaborados en los videos según estándares de revisión.

- Realizar el seguimiento de las competencias no aplicadas en el diseño del sitio web aplicando cada uno de los contenidos elaborados en los videos según estándares de revisión.

- Identificar la responsabilidad de cada alumno en el ingreso al aula virtual.

- Teniendo en cuenta la bibliografía se puede detectar:

- Responsables del Aprendizaje.

- Motivados por el Aprendizaje.

- Colaborativos.

- Estratégicos.

En el diseño y aplicación de cada elemento que se incorpora al aprendizaje y se integra en forma sucesiva durante el desarrollo de la Asignatura.

- Se puede observar que el 6\% de alumnos que no cumplieron con los objetivos de la Asignatura representan un promedio de 2 por cuatrimestre sobre un total de 16(dieciséis) obteniendo un amplio beneficio en la aplicación de competencias en la Asignatura Programación por intermedio de Flipped Classroom.

- Se puede determinar que se obtiene una aplicación adecuada de Competencias Aplicadas validando la hipótesis inicial.

- Fortalezas: 
- Se puede determinar la validación comprobable de la muestra.

- Identificar las competencias aplicadas en la Asignatura en los alumnos.

- Optimizar la evaluación de competencias aplicadas en la Asignatura Programación.

- Aplicación de competencias adquiridas en la formación académica de la Universidad de la Universidad Nacional de La Matanza en la Asignatura Programación en el ámbito laboral del estudiante.

- Elaborar metodologías de aprendizaje que le permitan al alumno el desarrollo de la estructura cognitiva del alumno de la Universidad Nacional de la Matanza en la Asignatura Programación en su modalidad de Taller.

- Incorporar nuevos elementos de aprendizaje a Flipped Classroom que le permitan al alumno la adquisición de un aprendizaje significativo del alumno de la Universidad Nacional de la Matanza en la Asignatura Programación en la modalidad de Taller.

- Elaborar metodologías de aprendizaje que le permitan al alumno la adquisición de un aprendizaje significativo del alumno de la UniversidadNacional de la Matanza en la Asignatura Programación en la modalidad de Taller.

- Mejorar continuamente la aplicación de nuevas metodologías de enseñanza en beneficio del alumno de la Universidad Nacional de la Matanza en la Asignatura Programación en la modalidad de Taller

\section{Debilidades:}

- El resultado del análisis cualitativo y cuantitativo obtenido en la aplicación de Competencias Aplicadas junto con el Análisis de Desviación permite puede observar cuales son las Competencias se aplican en forma inadecuada en la Asignatura Programaciónen la modalidad de Taller.

- Esta debilidad es un instrumento de aporte muy importante para poder corregir y actualizar el contenido de la Asignatura de Programación en la modalidad de Taller.

- Tomar decisiones validadas cuanti-tativamente y cualitativamente en la futura confección de los contenidos de la Asignatura Programación en la modalidad de Taller.

- Corregir desviaciones que se presentan en el desarrollo de la Asignatura Programación en la modalidad de Taller.

- Mejorar continuamente el desarro-llo de la Asignatura Programación en la modalidad de Taller. 


\section{Referencias}

Cobo Romaní, C. y Pardo Kuklinsky, H. (2007). Web 2.0. Inteligencia colectiva o medios fastfood. Grup de Recerca d'InteraccionsDigitals. Universidat de Vic. México: Flacso.

Hernandez Requena, S. (2008). "El modelo constructivista com La snuevastecnologías: aplicado enelproceso de aprendizaje" en RUSC, Revista de Universidad y SociedaddelConocimiento Vol. 5, n. 2: 26-35.

Martin-Moreno, Q. (2004). "Aprendizaje colaborativo y redes de conocimiento" en Actas de las IX Jornadas Andaluzas de Organización y Dirección de Instituciones Educativas. Granada: Grupo Edito $\neg$ rial Universitario: 55-70.

Bergmann, J., Sams, A. (2012). Flip your classroom: reach every students in every classevery day. Washington DC: ISTE.

TechSmith (2013). "Teachers Use Technology to Flip Their Classrooms".Disponible en <https://www.techsmith.com/education-flipped-classroom.html>.

Piaget, J. (1978). La representación del mundo en el niño. Madrid: Morata.

Vygotsky, L. S. (1978). Mind in society. Cambridge, MA: Harvard University Press.

Beltran Llera, J. A. (1996). Procesos, estrategias y técnicas de aprendizaje. Madrid: Síntesis.

Collazos, C., Guerrero, L., Vergara, A. (2001). "Aprendizaje Colaborativo: un cambio en el rol del profesor”. Memorias del III Congreso de Educación Superior en Computación. Jornadas Chilenas de la Computación. Punta Arenas Chile.

Spencer, L. M. y Spencer, S. M. (1993). Competence at Work. New York : John Wiley and Sons. 